\title{
EVA Regimen
}

National Cancer Institute

\section{Source}

National Cancer Institute. EVA Regimen. NCI Thesaurus. Code C63371.

A derivative of the orig inal ABVD regimen in which etoposide is substituted for the two drugs, bleomycin and dacarbazine, and is used for the treatment of relapsed or refractory Hodgkin lymphoma. 